\title{
An in-silico evaluation of COVID-19 main protease with clinically approved drugs
}

\author{
Tachoua Wafa ${ }^{a}$, Kabrine Mohamed ${ }^{b}$, Mamona Mushtaq ${ }^{c}$ and Zaheer Ul-Haq ${ }^{c}$
}

\section{*Corresponding author: Dr Tachoua Wafa.}

${ }^{\text {a } B e n y o u c e f ~ B e n k h e d d a ~ U n i v e r s i t y, ~ N a t u r e ~ a n d ~ L i f e ~ S c i e n c e s ~ d e p a r t m e n t, ~ D i d o u c h e ~ M o u r a d, ~}$ 16000, Algiers, Algeria.

${ }^{\mathrm{b}}$ University of Science and Technology Houari Boumediene, Faculty of Biological Sciences, Cellular and Molecular Biology, BP 32, El-Alia Bab Ezzouar, 16111, Algiers, Algeria.

${ }^{\mathrm{c}}$ Dr. Panjwani Center for Molecular Medicine and Drug Research, ICCBS, University of Karachi, Karachi-75270, Pakistan.

E-mail: wtachoua@yahoo.fr

E-mail: mohamed.kabrine@gmail.com

E-mail : maimoonamushtaq7@gmail.com

E-mail : zaheer.qasmi@iccs.edu

\begin{abstract}
A novel strain of coronavirus, namely, SARS-CoV-2 identified in Wuhan city of China in December 2019, continues to spread at a rapid rate worldwide. There are no specific therapies available and investigations regarding the treatment of this disease are still lacking. In order to identify a novel potent inhibitor, we performed blind docking studies on the main virus protease $\mathrm{M}^{\text {pro }}$ with eight approved drugs belonging to four pharmacological classes such as: anti-malarial, anti-bacterial, anti-infective and anti-histamine. Among the eight studied compounds, Lymecycline and Mizolastine appear as potential inhibitors of this protease. When docked against $\mathrm{M}^{\text {pro }}$ crystal structure, these two compounds revealed a minimum binding energy of -8.87 and $-8.71 \mathrm{kcal} / \mathrm{mol}$ with 168 and 256 binding modes detected in the binding substrate pocket, respectively. Further, to study the interaction mechanism and conformational dynamics of protein-ligand complexes, Molecular dynamic simulation and MM/PBSA binding free calculations were performed. Our results showed that both Lymecycline and Mizolastine bind in the active site. And exhibited good binding affinities towards target protein. Moreover, the ADMET analysis also indicated drug-likeness properties. Thus it is suggested that the identified compounds can inhibit Chymotrypsin-like protease $\left(3 \mathrm{CL}^{\text {pro }}\right)$ of SARS-CoV-2.
\end{abstract}

Key words: COVID-19 Main protease; Molecular docking; SwissDock; Approved drugs; MD simulation; ADMET. 


\section{Introduction}

The outbreak of the novel coronavirus disease, COVID-19, caused by coronavirus 2019nCoV officially designated as severe acute respiratory syndrome related coronavirus 2 (SARS-CoV-2), represents a pandemic threat to global public health (Gorbalenya et al., 2020; Kupferschmidt \& Cohen, 2020). On January 30, the World Health Organization (WHO) announced a Public Health Emergency of International Concern (PHEIC) for the 2019-nCoV outbreak (Rodríguez-Morales et al., 2020).

Coronaviruses are relatively large viruses containing a single stranded positive-sense RNA genome encapsulated within a membrane envelope. The viral membrane is studded with glycoprotein spikes that give coronaviruses their crown-like appearance. There are four classes of coronaviruses, namely alpha, beta, gamma and delta. The beta-coronavirus class include severe acute respiratory syndrome virus (SARS-CoV), the middle east respiratory syndrome virus (MERS-CoV), and the newly identified severe acute respiratory syndrome coronavirus 2 (SARS-CoV-2) (Anthony et al., 2017). Although SARS-CoV-2 is classified into beta-coronaviruses group, it is diverse from MERS-CoV and SARS-CoV. It has been reported that SARS-CoV-2 genes share less than $80 \%$ identity (nucleotides) with SARS-CoV and it is more transmissible than other SARS-CoV viruses (Kucharski et al., 2020; Wu et al., 2020; Zhou et al., 2020).

The SARS-CoV-2 genome consists of approximately 30000 nucleotides. It encodes several structural proteins such as the glycosylated spike protein $(S)$, envelope protein $(E)$, membrane protein $(\mathrm{M})$, and nucleocapsid protein $(\mathrm{N})$. Additionally, the viral genome also encodes numerous nonstructural proteins, including RNA-dependant RNA polymerase (RdRp), coronavirus main protease $\left(\mathrm{M}^{\mathrm{pro}}\right)$, and papain-like protease (PLpro). Upon entrance in the host cell, the viral genome is released and subsequently translated into viral poly-proteins using host cell translation machinery. The poly-proteins are then cleaved into effector proteins by viral proteases PLpro and $\mathrm{M}^{\text {pro }}$ (Anand et al., 2003; Liu et al., 2020). The $\mathrm{M}^{\text {pro }}$, also known as 3 -chymotrypsin-like protease $(3 \mathrm{CL})$, plays a critical role in the virus replication process. It cleaves pp1a and pp1b polyproteins subsequently releasing functional proteins including RNA polymerase, endoribonuclease and exoribonuclease. Therefore, $\mathrm{M}^{\text {pro }}$ is a potential target for anti-coronaviruses screening. Indeed, inhibiting $\mathrm{M}^{\text {pro }}$ activity could stop the spread of infection (Needle et al., 2015; Elmezayen et al., 2020).

The released crystal structure of $\mathrm{M}^{\text {pro }}$ (6lu7) was obtained by a co-crystallization with a peptide-like inhibitor called N3 (PRD_002214). The enzyme has a molecular weight of 33.79 $\mathrm{kDa}$ as determined by Mass spectroscopy. $\mathrm{M}^{\text {pro }}$ forms a dimer, where each monomer comprises three domains: Domain I (residues 8-101) and II (102-184) consists of an antiparallel beta barrel, and the alpha helical domain III (residues 201-301) is required for enzymatic activity. It shares a similar structure with cysteine protease, however the active site lacks the third catalytic residue. Thus, catalytic harbors Histidine 41 (H41) and Cysteine 145 (C145) (Boopathi et al., 2020; Jin et al., 2020) located in between domain I and II, while amino acids, T24, L27, H41, F140, C145, H163, M165, P168 and H172 form a hydrophobic surrounding in the pocket (Yang et al., 2003). 
The concept of drug repurposing is widely used nowadays to identify potential drugs for COVID-19 disease. The practice of reusing drugs for more than one purpose can significantly reduce the cost, time and risks of the drug development process (Muralidharan et al., 2020).

To date many studies have targeted SARS-CoV-2 $\mathrm{M}^{\text {pro }}$. Of them, the study of Khan and collaborators, based on computational drug design methods, yielded five promising hits corresponding to three antiviral drugs (Remdesivir, Saquinavir and Darunavir) and two natural compounds (Flavone and coumarine) (Khan et al., 2020). Similarly, Aanouz and collaborators proposed three compounds (Corcin, Digitoxigenin, and $\beta$-Eudesmol) as potential inhibitors of $\mathrm{M}^{\text {pro }}$ from Moroccan medicinal plants (Aanouz et al., 2020). Interestingly, Talampicillin and Lurasidone are reported to possess the highest affinity towards $\mathrm{M}^{\text {pro }}$ enzyme and might be repurposed against COVID-19 (Elmezayen et al., 2020).

Although, several molecular docking studies have been established to find a potential inhibitor of $\mathrm{M}^{\text {pro }}$ activity based on antiviral compounds commonly used to treat immunodeficiency virus (HIV), phytochemical, antimalarial agents, spices or marine products (Chang et al., 2020; Islam et al., 2020; Khan et al., 2020; Srivastava et al., 2020; Umesh et al., 2020). Unfortunately, no specific therapies for COVID-19 disease are available and investigations regarding the treatment of COVID-19 disease are still lacking. Therefore, there is a dire need to identify approved drugs which may inhibit SARS-CoV-2 virus proteins and to find at the same time their optimal association and concentration to treat COVID-19 patients.

In the following study, we investigate the $\mathrm{M}^{\text {pro }}$ inhibitory potential of eight clinically approved drugs belonging to four pharmacological classes: anti-viral, anti-bacterial, antiinfective and anti-histamine, using a molecular docking and a molecular dynamics approach.

\section{Methods}

\subsection{Target and ligand retrieval form databases}

This research is a descriptive-analytical study. In this study, the interaction of several approved compounds was investigated. A total of eight compounds were tested against COVID-19 main protease ( $\mathrm{M}^{\mathrm{pro}}$ ). N3 compound was used as a docking target for comparison.

In order to obtain the structure information of selected compounds, a Drugbank database (https://www.drugbank.ca/) was used (Wishart et al., 2006) (Table I). The Three dimensional structure of $\mathrm{M}^{\text {pro }}$ (Figure 1) was retrieved from the Protein Data Bank (PDB) (https://www.rcsb.org/) (Bernstein et al., 1977). It corresponds to a complex between the enzyme and its inhibitor N3 (Jin et al., 2020). The 6lu7 structure preparation consists of several steps such as deleting all water molecules, N3 inhibitor and adding hydrogens. The new file was saved for docking analysis. 
Table I: List of approved compounds used in this study. a: Drug bank accession number, b: Antibiotic, MM: Molecular Mass

\begin{tabular}{|c|c|c|c|c|}
\hline Compound & $\begin{array}{l}\text { Accession } \\
\text { number }^{a}\end{array}$ & Drug class & $\begin{array}{l}\mathrm{MM} \\
\mathrm{g} / \mathrm{mol}\end{array}$ & Description \\
\hline Chloroquine & DB00608 & Aminoquinolone derivative & 319.87 & Antimalarial \\
\hline Quinine & DB00468 & Alkaloid & 324.41 & Antimalarial \\
\hline Nitazoxanide & DB00507 & Thiazolide & 307.28 & Anti-infective \\
\hline Doxycycline & DB00254 & Oxytertacycline derivative $\mathrm{ATB}^{\mathrm{b}}$ & 444.43 & Antibacterial \\
\hline Lymecycline & DB00256 & $\begin{array}{l}\text { Tetracycline with a 7-chloro } \\
\text { substitution }\end{array}$ & 602.63 & Antibacterial \\
\hline Cetirizine & DB00341 & Histamine $\mathrm{H} 1$ antagonist & 388.88 & Antihistamine \\
\hline Mizolastine & DB12523 & Histamine $\mathrm{H} 1$ antagonist & 432.50 & Antihistamine \\
\hline Indinavir & DB00224 & Specific HIV protease inhibitor & 613.78 & Antiviral \\
\hline
\end{tabular}
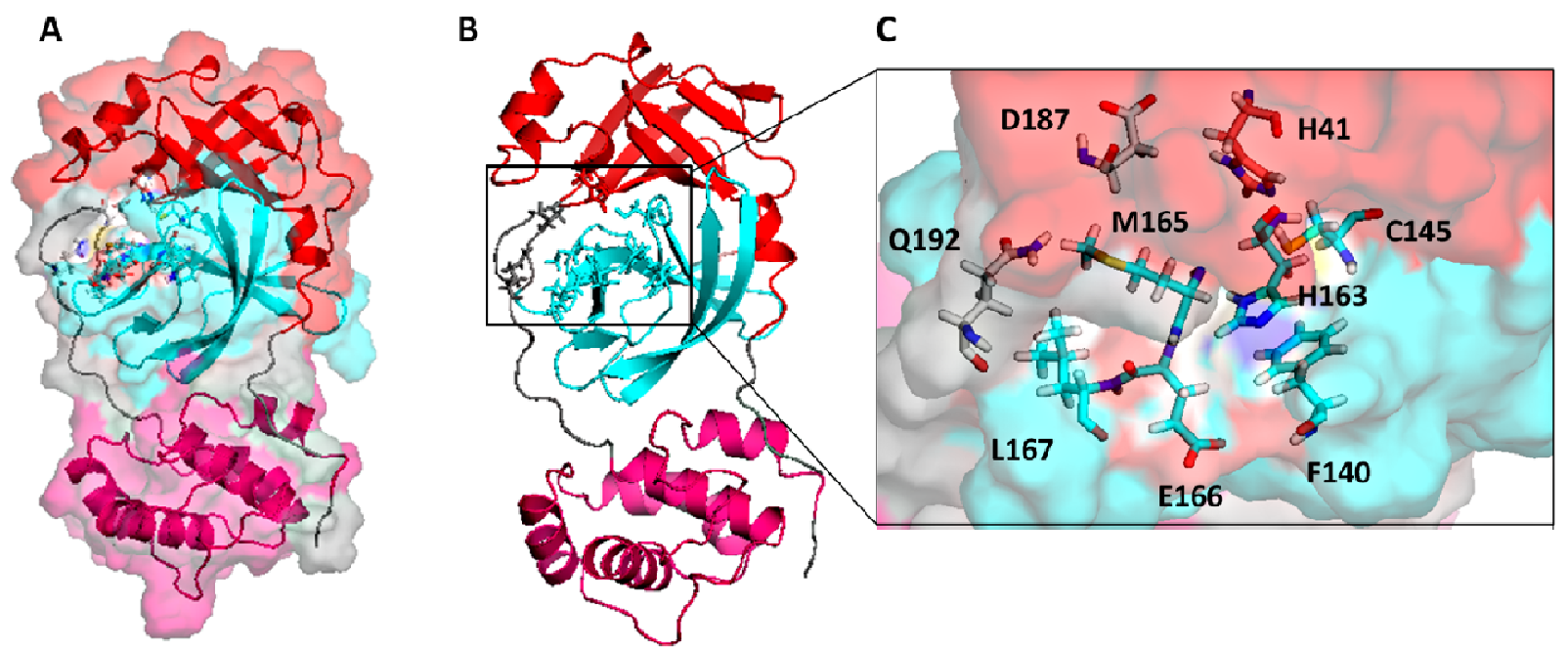

Figure 1: Pymol Structure representation of $\mathrm{M}^{\text {pro }}$. Surface (A) and Cartoon (B) representations of one protomer of the dimeric $\mathrm{CoV} \mathrm{M}^{\text {pro }}$. (C) Surface and stick representations of the conserved binding pocket of $\mathrm{M}^{\text {pro }}$. Red color: $\mathrm{M}^{\text {pro }}$ domain I, Bleu color: $\mathrm{M}^{\text {pro }}$ domain II and pink color for $\mathrm{M}^{\text {pro }}$ domain III. Gray color represents coils. $\mathrm{C}(\mathrm{Cys})$, D(Asp), E(Glu), F(Phe), H(His), L(Leu), M(Met), Q(Gln).

\subsection{Blind docking}

In order to investigate the molecular interaction between several approved compounds and COVID-19 main protease $\left(\mathrm{M}^{\mathrm{pro}}\right)$, blind docking was performed using a SwissDock server (http://www.swissdock.ch/) under the accurate mode with no flexibility of the side chain of any amino acid of the target protein. In addition, a binding pocket was not defined so as not to bias the docking towards the active site. The protein and ligand were specified by uploading PDB and Mol2 files, respectively. 
SwissDock generates all possible binding modes for each ligand and the most favorable binding modes at a given pocket were clustered. All ligand clusters were saved in an output file called "prediction file". The prediction file provided; Cluster rank, Element, Fulfitness and estimated binding free energy $(\Delta G)$. A cluster corresponds to a predicted binding pocket on the target protein and the cluster rank represents the different conformations of a ligand in a certain cluster (Grosdidier et al., 2011). Only the lowest energy model of cluster zero was considered to be the most favorable interaction.

\subsection{Clusters visualization and $2 \mathrm{D}$ diagrams generation}

After docking Chimera and Pymol softwares were used to visualize the receptor ligand interactions for the lowest energy model of the clusters obtained from the previous step. Each ligand cluster was inspected for amino acids interacting with the ligand, hydrogen bonds $(\mathrm{H}-$ bonds), the specific atoms involved. All the interacting amino acids with the target were noted for each cluster (DeLano, 2002; Pettersen et al., 2004).

2D diagrams were generated by PoseView integrated into Proteins Plus server (https://proteinsplus.zbh.uni-hamburg.de/\#dogsite) (Fährrolfes et al., 2017), which automatically creates two-dimensional diagrams of protein ligand complexes according to chemical drawing conventions. The generation of structure diagrams and their layout modifications are based on the library 2Ddraw. Interactions between the molecules are estimated by a builtin interaction model that is based on atom types and simple geometric criteria (Fricker et al., 2004; Stierand et al., 2006).

\subsection{Binding pocket prediction}

Although the binding site is well characterized for $\mathrm{N} 3$ within many $\operatorname{CoV} \mathrm{M}^{\text {pro }}$ crystals. We have applied the DoGSiteScorer online tool (https://proteinsplus.zbh.unihamburg.de/\#dogsite) to predict and describe binding pockets within native $\mathrm{M}^{\text {pro }}$ and the complexes $\mathrm{M}^{\mathrm{pro}} /$ inhibitors obtained after docking analysis.

DoGSiteScorer is a grid-based method which uses a Difference of Gaussian filter to detect potential binding pockets solely based on the 3D structure of the protein and splits them into subpockets. Global properties, describing the size, shape and chemical features of the predicted (sub) pockets are calculated. Per default, a simple druggability score is provided for each (sub) pocket, based on a linear combination of the three descriptors describing volume, surface, hydrophobicity and enclosure. Furthermore, a subset of meaningful descriptors is incorporated in a support vector machine (libsvm) to predict the (sub) pocket druggability score (values are between zero and one). The binding pockets are ranked according to their size, surface area and druggability score (Volkamer et al., 2015).

\subsection{Drug likeliness, pharmacokinetic and oral toxicity evaluations}

To analyze drug likeliness and the pharmacokinetics parameters, all the molecules were subjected to ADME (Absorption, distribution, metabolism and excretion) predictions with SwissADME tool (http://www.swissadme.ch/) (Daina et al, 2017). The oral toxicity and 
$\mathrm{LD}_{50}$ (Lethal dose, $50 \%$ ) of selected drugs was also analyzed by using the PROTOX web server (http://tox.charite.de/protox_II/) (Drwal et al., 2014).

\subsection{Molecular dynamics simulation}

The molecular dynamics simulation (MD) was performed on the best two compounds obtained from molecular docking study (Lymecycline and Mizolastine), which helped to get more insight into the protein and docked complexes in biological conditions.

To gain atomic level insight into the binding interaction of Lymecycline and Mizolastine with SARS-Cov2 $\mathrm{M}^{\text {pro }}$, all atom-molecular dynamics simulations were carried out using PMEMD.cuda module implemented in AMBER 18 with explicit water model under periodic boundary conditions (Case et al, 2005). The parameters for both systems $\left(\mathbf{M}^{\text {pro }}\right.$ Lymecycline and $\mathrm{M}^{\text {pro }}$-Mizolastine) were prepared using the antechamber and tleap modules. Amber ff14SB (Maier et al., 2015) force field was assigned to protein whilst Amber Generalised Force Field (GAFF) (Wang et al., 2004) was selected for the two compounds. Each system was solvated using the TIP3P water model in a periodic box, with a minimum spacing of $10 \AA$ from the solute/protein atoms. After that neutralization of the system with counter ions $\left(\mathrm{Na}^{+}\right)$replacing solvent molecules at the position of electrostatic favorable potential. The Particle Mesh Ewald Method (PMEM) and the SHAKE algorithm were used to calculate the long-range electrostatic interactions and to constrain the hydrogen bonds respectively (Darden et al., 1993, Ryckaert et al., 1977). To remove bad contacts and possible steric clashes both complexes were subjected to energy minimization. Briefly systems were relaxed by adjusting hydrogen position, whereas the first 1000 cycles were carried out using steepest descent algorithm and the next 5000 steps involved the conjugate gradient algorithm with heavy atoms restrained by the force of $100 \mathrm{kcal} / \mathrm{mol}$. It was followed by 5000 additional minimization steps in absence of any restraint. Afterwards each system was equilibrated under NVT (gradual heating from $0 \mathrm{~K}$ to $300 \mathrm{~K}$ ) and NPT (pressure $=1 \mathrm{~atm}$ ) ensembles. The final production run of $75 \mathrm{~ns}$ was performed at constant temperature $(300 \mathrm{~K})$ and pressure $(1 \mathrm{~atm})$ with integration time steps of 2 fs. The obtained results were analyzed via CPPTRAJ modules. Chimera and VMD were used for visualization and the graphs were plotted using Xmgrace tool (Humphrey et al., 1996, Pettersen et al., 2004).

\subsection{Energy calculations}

To estimate the binding free energies of the selected inhibitors against SARS-CoV-2 $\mathrm{M}^{\text {pro }}$, the widely known MM-PBSA was performed. This tool computes components of binding free energy utilizing the molecular mechanics/Poisson-Boltzmann surface area (MM/PBSA), implemented in AMBER 18. A total of 2500 frames were extracted from the last 10 nanoseconds simulation trajectory.

In the MMPBSA protocol, the following equation is used to calculate binding free energy $\left(\Delta \mathrm{G}_{\mathrm{bind}}\right)$ of an inhibitor.

$$
\Delta \text { Gbind }=\Delta \mathrm{H}-\mathrm{T} \Delta \mathrm{S} \approx \Delta \mathrm{EMM}+\Delta \mathrm{Gsolv}-\mathrm{T} \Delta \mathrm{S}
$$




$$
\begin{gathered}
\Delta \mathrm{EMM}=\Delta \text { Einternal }+\Delta \text { Eelec }+\Delta \text { EvdW } \\
\Delta \text { Gsolv }=\Delta \mathrm{Gpol}+\Delta \mathrm{Gnp}
\end{gathered}
$$

Where $\Delta \mathrm{E}_{\mathrm{MM}}$ represents the alterations in molecular mechanics energy at gas phase, $\Delta \mathrm{G}_{\text {solv }}$ and $-\mathrm{T} \Delta \mathrm{S}$ indicate desolvation free energy and the conformational entropic contributions upon binding with ligand, respectively. Further, $\Delta \mathrm{E}_{\mathrm{MM}}$ is sum of $\Delta \mathrm{E}_{\text {internal }}$ (bond, dihedral and angle energies), $\Delta \mathrm{E}_{\text {elec }}$ (electrostatic), and $\Delta \mathrm{E}_{\mathrm{vdW}}$ (van der Waals) energies while $\Delta \mathrm{G}_{\mathrm{pol}}$ and $\Delta \mathrm{G}_{\mathrm{np}}$ represents polar and nonpolar solvation energy (Miller et al., 2012).

\section{Results and discussion}

\subsection{Molecular docking}

In order to investigate the possible mechanism by which selected drugs act, an silico theoretical molecular docking approach was used.

During our study, we simulated the binding mode of N3 against 6lu7 crystal structure using SwissDock to ensure the effectiveness of docking results and to compare results produced by several drugs to those of N3. Indeed, this compound is a well characterized inhibitor of COVID-19 main protease.

Docking results revealed that N3, Indinavir and Chloroquine had the best energies of binding $-10.83,-9.81$ and $-9.71 \mathrm{kcal} / \mathrm{mol}$, respectively (Table II, column 5), which is consistent with three studies. The first one reported the entire complex N3/M $\mathrm{M}^{\text {pro }}$ crystal structure saved in the PDB database under 6lu7 accession number (Jin et al., 2020). The second reported that Indinavir presented a best docking score with a minimum energy of $-10.41 \mathrm{kcal} / \mathrm{mol}$ using the Autodock Vina tool (Chang et al, 2020) and the last one based on molecular docking of antimalarial agents against 6lu7 crystal structure, which revealed that Chloroquine bind to $\mathrm{M}^{\text {pro }}$ with $-8.15 \mathrm{kcal} / \mathrm{ml}$ binding energy (Srivastava et al., 2020).

According to a full fitness score, Lymecycline and Mizolastine had more favorable binding mode, indicated by more negative fullfitness scores -1332.56 and $-1300.12 \mathrm{kcal} / \mathrm{mol}$, respectively (Table II, column 4). Azelastine can undergo an optimal binding with $\mathbf{M}^{\text {pro }}$ (Odhar et al., 2020). When the clusters were analyzed it was found that N3, Indinavir, Chloroquine and Mizolastine showed that all clusters were able to fit into $\mathrm{M}^{\text {pro }}$ binding pocket. However, Lymecycline revealed a binding energy of $-8.87 \mathrm{kcal} / \mathrm{mol}$ and it was able to occupy 23 clusters constituting a total of 168 possible conformations within the substrate binding cavity, out of a total of 256 elements (Table II, column 3). It is striking that all or more than half of the total predicted elements are docked in the substrate binding pocket.

To investigate the possible reasons for differences in the binding energies, we examined the docked complexes with Pymol software and PoseView integrated in Protein Plus server. Table II showed the number and length of H-bonds formed between the target protease and the different compounds. Chloroquine, Nitazoxanide and Cetirizine established only one $\mathrm{H}$ - 
bond with N142, E166 and N142 residues, respectively. Otherwise, Quinine, Doxycycline and Indinavir were found to form two H-bonds with E166, E166 and (L141, Gly143) residues, respectively. Interestingly, Mizolastine and Lymecycline were found to form three H-bonds with $\mathrm{M}^{\text {pro }}$. Indeed, Lymecycline established three specific H-bounds (two H-bonds with E166 residue and one H-bond with Q189 residue) (Figure 3A, and C). However, Mizolastine formed three H-bonds (two H-bonds with T24 residue and one with G143) and hydrophobic interactions with N142 and C145 residues (Figure 3B and D).

N3 compound forms multiple hydrogen bonds with the main chain of residues in the substrate-binding pocket (Jin et al., 2020). However, only two hydrogen bonds were detected after SwissDock analysis because the complex of $\mathrm{M}^{\text {pro }}$ with its inhibitor N3 was obtained in theoretical (in silico) not in experimental conditions.

Although Lymecycline and Doxycycline belong to the same family of tetracyclines, Lymecycline bind more effectively to $\mathrm{M}^{\text {pro }}$ with a minimum energy of $-8.87 \mathrm{kcal} / \mathrm{mol}$ compared to Doxycycline with $-7.52 \mathrm{kcal} / \mathrm{mol}$ binding energy, suggesting, the role of $\mathrm{NH}$ $(\mathrm{CH} 2)_{4} \mathrm{CH} \mathrm{COOH} \mathrm{NH} 2$ chemical substituting group in increasing the binding affinity of Lymecycline towards $\mathrm{M}^{\text {pro }}$ enzyme.

Table II: Molecular docking analysis results for several drugs against 6lu7 crystal structure. These drugs were ranked according to their minimum binding energy. The lowest energy model of cluster rank zero was considered.

\begin{tabular}{|c|c|c|c|c|c|c|c|}
\hline Compounds & Clusters & $\begin{array}{l}\text { Total } \\
\text { elements }\end{array}$ & $\begin{array}{l}\text { Fullfitness } \\
\text { (kcal/mol) }\end{array}$ & $\begin{array}{l}\Delta \mathrm{G} \\
(\mathrm{kcal} / \mathrm{mol})\end{array}$ & $\begin{array}{l}\mathrm{H}- \\
\text { bonds }\end{array}$ & $\begin{array}{l}\text { Length } \\
(\AA)\end{array}$ & Residues \\
\hline \multirow{2}{*}{ N3 } & \multirow{2}{*}{$38 / 38$} & \multirow{2}{*}{$256 / 256$} & \multirow{2}{*}{-1172.91} & \multirow{2}{*}{-10.83} & \multirow{2}{*}{2} & 2.1 & G143 \\
\hline & & & & & & 2.8 & Q189 \\
\hline \multirow{2}{*}{ Indinavir } & \multirow{2}{*}{$54 / 54$} & \multirow{2}{*}{$256 / 256$} & \multirow{2}{*}{ |-1098.93 } & \multirow{2}{*}{-9.81} & \multirow{2}{*}{2} & 2.7 & L141 \\
\hline & & & & & & 2.6 & G143 \\
\hline \multirow[t]{2}{*}{ Chloroquine } & \multirow[t]{2}{*}{$44 / 44$} & \multirow[t]{2}{*}{$254 / 254$} & \multirow{2}{*}{-1223.94} & \multirow[t]{2}{*}{-9.71} & \multirow[t]{2}{*}{1} & 2.6 & N142 \\
\hline & & & & & & 2.2 & E166 \\
\hline \multirow[t]{2}{*}{ Lymecycline } & \multirow[t]{2}{*}{$23 / 33$} & \multirow[t]{2}{*}{$168 / 256$} & \multirow[t]{2}{*}{-1332.56} & \multirow[t]{2}{*}{-8.87} & \multirow[t]{2}{*}{3} & 2.3 & E166 \\
\hline & & & & & & 2.9 & Q189 \\
\hline \multirow{3}{*}{ Mizolastine } & \multirow{3}{*}{$54 / 54$} & \multirow{3}{*}{$256 / 256$} & \multirow{3}{*}{-1300.12} & \multirow{3}{*}{-8.71} & \multirow{3}{*}{3} & 2.3 & G143 \\
\hline & & & & & & 2.5 & \multirow{2}{*}{$\mathrm{T} 24$} \\
\hline & & & & & & 2.1 & \\
\hline Quinine & $39 / 40$ & $242 / 250$ & -1135.13 & -8.09 & 2 & 2.6 & E166 \\
\hline Cetirizine & $38 / 42$ & $224 / 256$ & -1112.62 & -7.99 & 1 & 2.1 & N142 \\
\hline Nitazoxanide & $58 / 64$ & $224 / 256$ & -1215.20 & -7.77 & 1 & 2.1 & E166 \\
\hline Doxycycline & $22 / 32$ & $176 / 256$ & -1276.83 & -7.52 & 2 & $2 / 2.4$ & E166 \\
\hline
\end{tabular}

Column 2 represents clusters within $\mathrm{M}^{\text {pro }}$ binding pocket/total clusters

Column 3 represents the number of conformations within the $\mathrm{M}^{\text {pro }}$ binding pocket/Total elements. E(Glu), G(Gly), L(Leu), N(Asn), Q(Gln), T(Thr). 


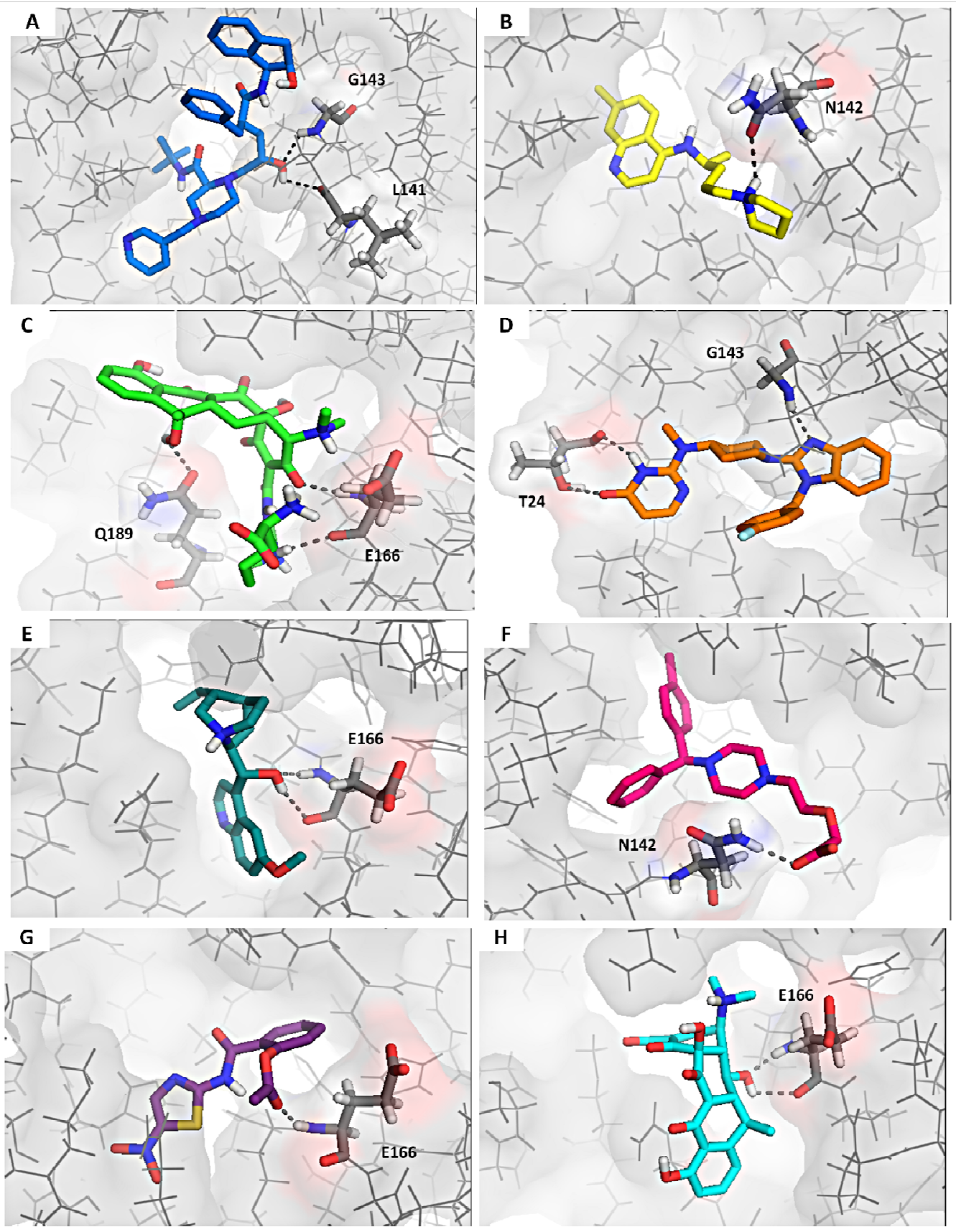

Figure 2: Docking poses of different drugs against $\mathrm{M}^{\text {pro }}$ visualized by Pymol. The protease $\mathrm{M}^{\text {pro }}$ is shown as gray background, inhibitors are in different colors. (A) Indinavir. (B) Chloroquine. (C) Lymecycline. (D) Mizolastine. (E) Quinine. (F) Cetirizine. (G) Nitazoxanide. $(\mathrm{H})$ Doxycycline. H-bonds are represented by black dashed lines. Interacting residues are labeled: E (Glu), G (Gly), H (His), L (Leu), N (Asn), Q (Gln), T (Thr). 
A

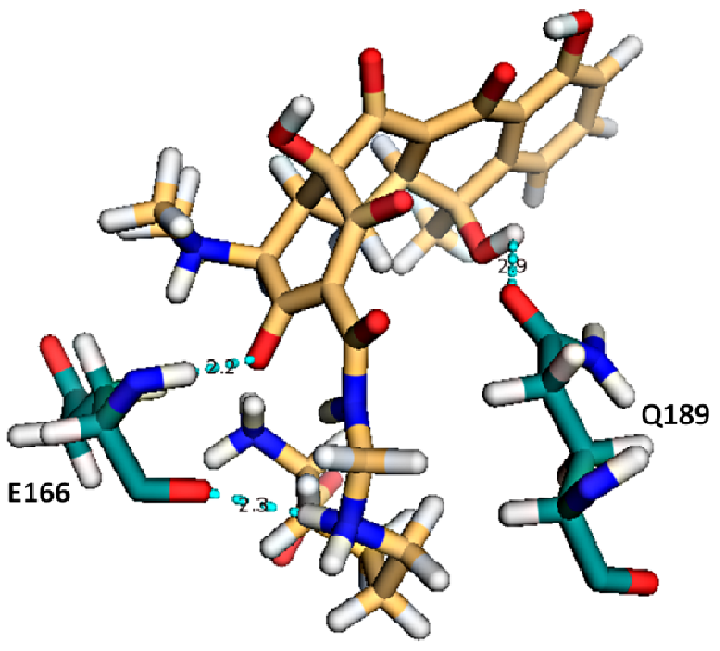

C

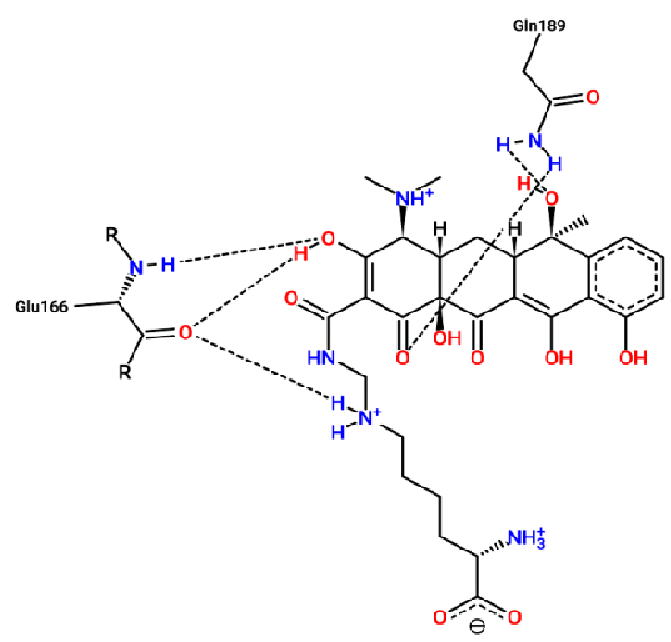

B

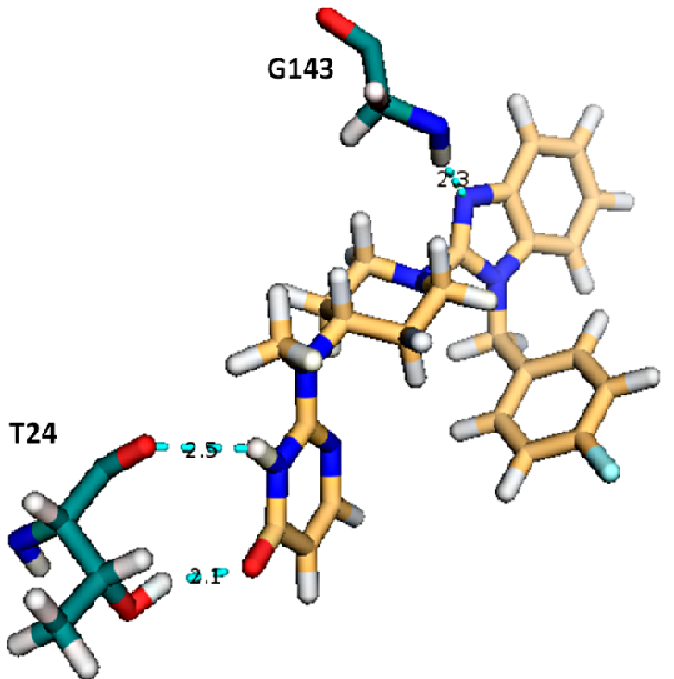

D

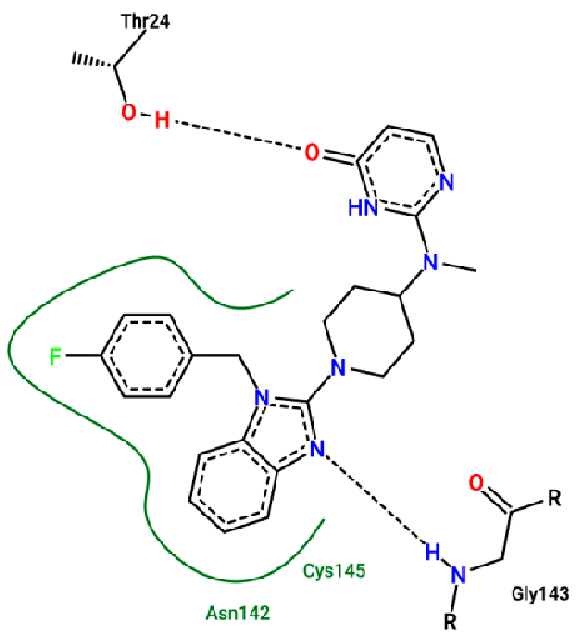

Figure 3: Interactions established after docking of Lymecycline and Mizolastine with 6lu7 $\mathrm{M}^{\text {pro }}$ protease. Three dimensional representation of intermolecular interaction in (A) Complex Lymecycline/6lu7 $\mathrm{M}^{\text {pro }}$, (B) Complex Mizolastine/6lu7 $\mathrm{M}^{\text {pro }}$ (Cyan dashed lines depict hydrogen bonds). 2D plot showing both hydrogen and hydrophobic interactions in (B) Complex Lymecycline/6lu7 $\mathrm{M}^{\mathrm{pro}}$, (C) Complex Mizolastine/6lu7 $\mathrm{M}^{\text {pro }}$. Directed bonds between protein and ligand are drawn as black dashed lines and the interacting protein residues and the ligand are visualized as structure diagrams. Hydrophobic contacts are represented more indirectly by means of spline sections highlighting the hydrophobic parts of the ligand and the label of the contacting amino acid. 


\subsection{Binding pockets prediction}

To elucidate and describe binding pockets within $\mathrm{M}^{\text {pro }}$, Dogsitescorer server was used to analyze unliganded structure (6lu7) and N3/6lu7, Lymecycline/6lu7, Mizolastine/6lu7 complexes. Here, we have reported only the first three pockets in Table III. Results revealed that N3, Lymecycline and Mizolastione occupied the same pocket (P0) within 6lu7 structure (Figure 4) with a high druggability score of 0.8 and a volume of 1191.74, 1061.18 and $1266.18 \AA^{3}$, respectively.

Based on Docking and Dogsitescorer studies, it is evident that Lymecycline and Mizolastine showed favorable binding with the new $\mathrm{M}^{\text {pro }}$, and the data comparable with those of N3. 
Table III: Binding pockets prediction for chain A of $\mathrm{M}^{\text {pro }}$ structure (6lu7) in complex with inhibitors (N3, Lymecycline and Mizolastine).

\begin{tabular}{|c|c|c|c|c|c|c|}
\hline Structure & $\begin{array}{l}\text { Pocket } \\
\text { Number }\end{array}$ & $\begin{array}{l}\text { Volume } \\
\left(\AA^{3}\right)\end{array}$ & $\begin{array}{l}\text { Surface } \\
\left(\AA^{2}\right)\end{array}$ & $\begin{array}{l}\text { Drug } \\
\text { score }\end{array}$ & $\begin{array}{l}\text { Hydrophobicity } \\
\text { ratio }\end{array}$ & Enclosure \\
\hline \multirow[t]{3}{*}{$61 \mathrm{lu}$} & 0 & 702.27 & 842.81 & 0.77 & 0.35 & 0.13 \\
\hline & 1 & 374.59 & 757.16 & 0.74 & 0.48 & 0.11 \\
\hline & 2 & 330.18 & 518.79 & 0.56 & 0.40 & 0.24 \\
\hline \multirow[t]{3}{*}{$61 \mathrm{u} 7+\mathrm{N} 3$} & 0 & 1191.74 & 1136.13 & 0.8 & 0.34 & 0.1 \\
\hline & 1 & 257.79 & 538.69 & 0.56 & 0.43 & 0.08 \\
\hline & 2 & 253.7 & 544.53 & 0.51 & 0.49 & 0.24 \\
\hline \multirow[t]{3}{*}{ 6lu7+Lymecycline } & 0 & 1061.18 & 1032.51 & 0.8 & 0.35 & 0.08 \\
\hline & 1 & 292.67 & 475.29 & 0.51 & 0.39 & 0.25 \\
\hline & 2 & 277.7 & 601.59 & 0.65 & 0.47 & 0.1 \\
\hline \multirow[t]{3}{*}{ 6lu7/Mizolastine } & 0 & 1266.18 & 1294.39 & 0.8 & 0.32 & 0.09 \\
\hline & 1 & 272.13 & 514.16 & 0.64 & 0.34 & 0.1 \\
\hline & 2 & 272.06 & 488.48 & 0.5 & 0.49 & 0.24 \\
\hline
\end{tabular}




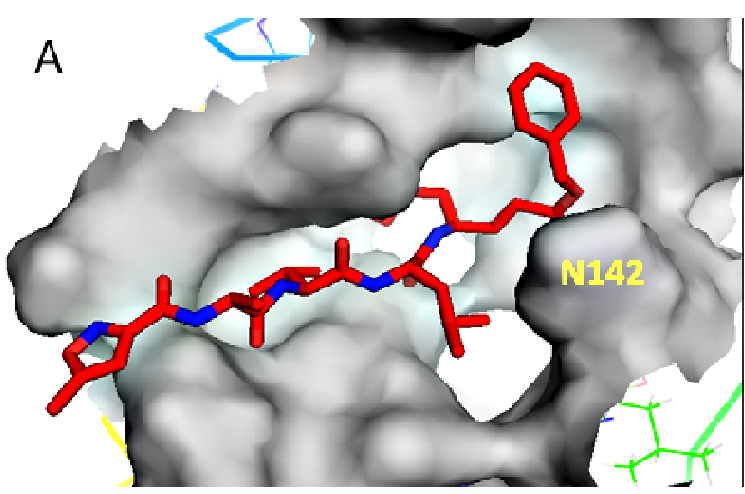

D
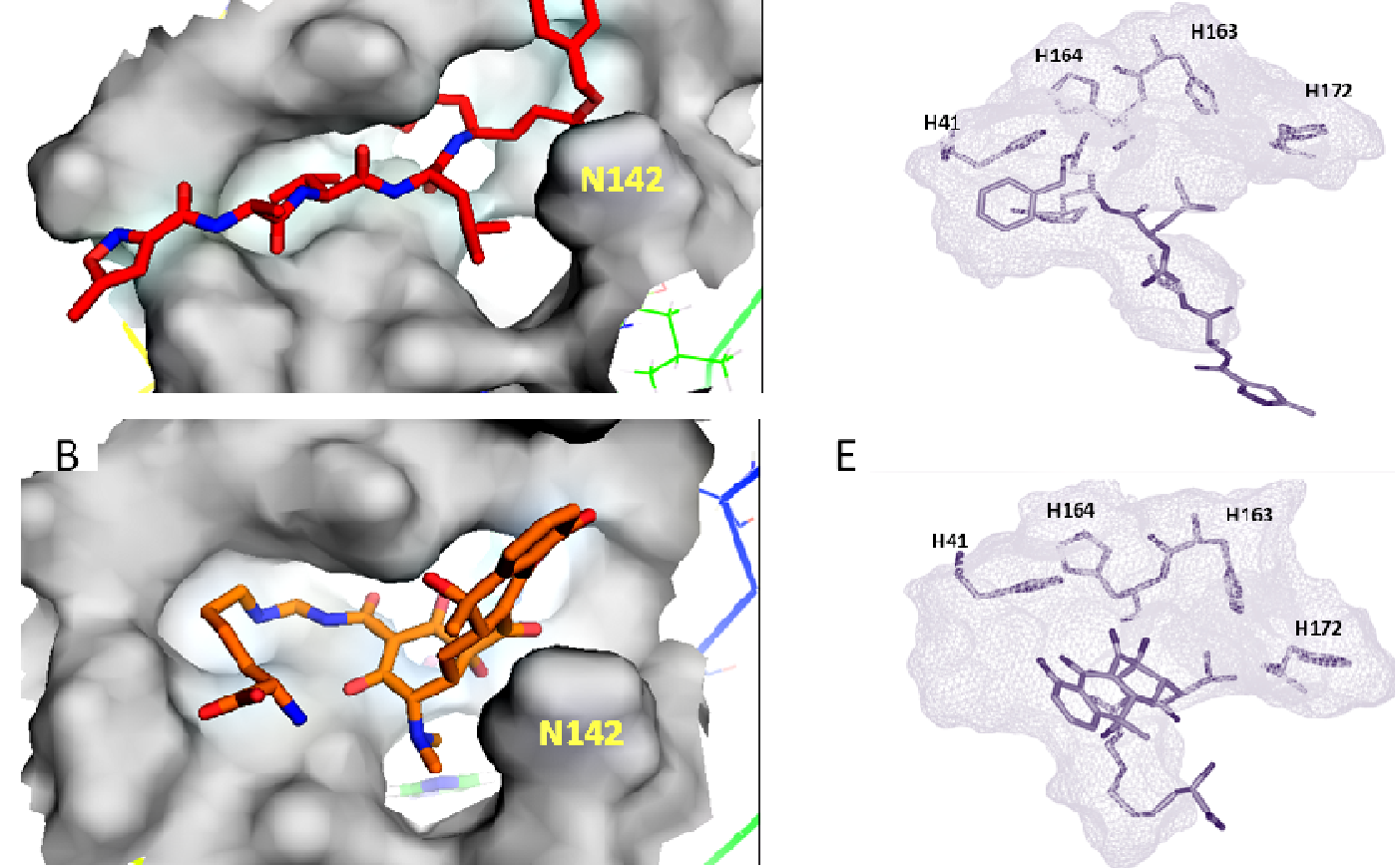

E
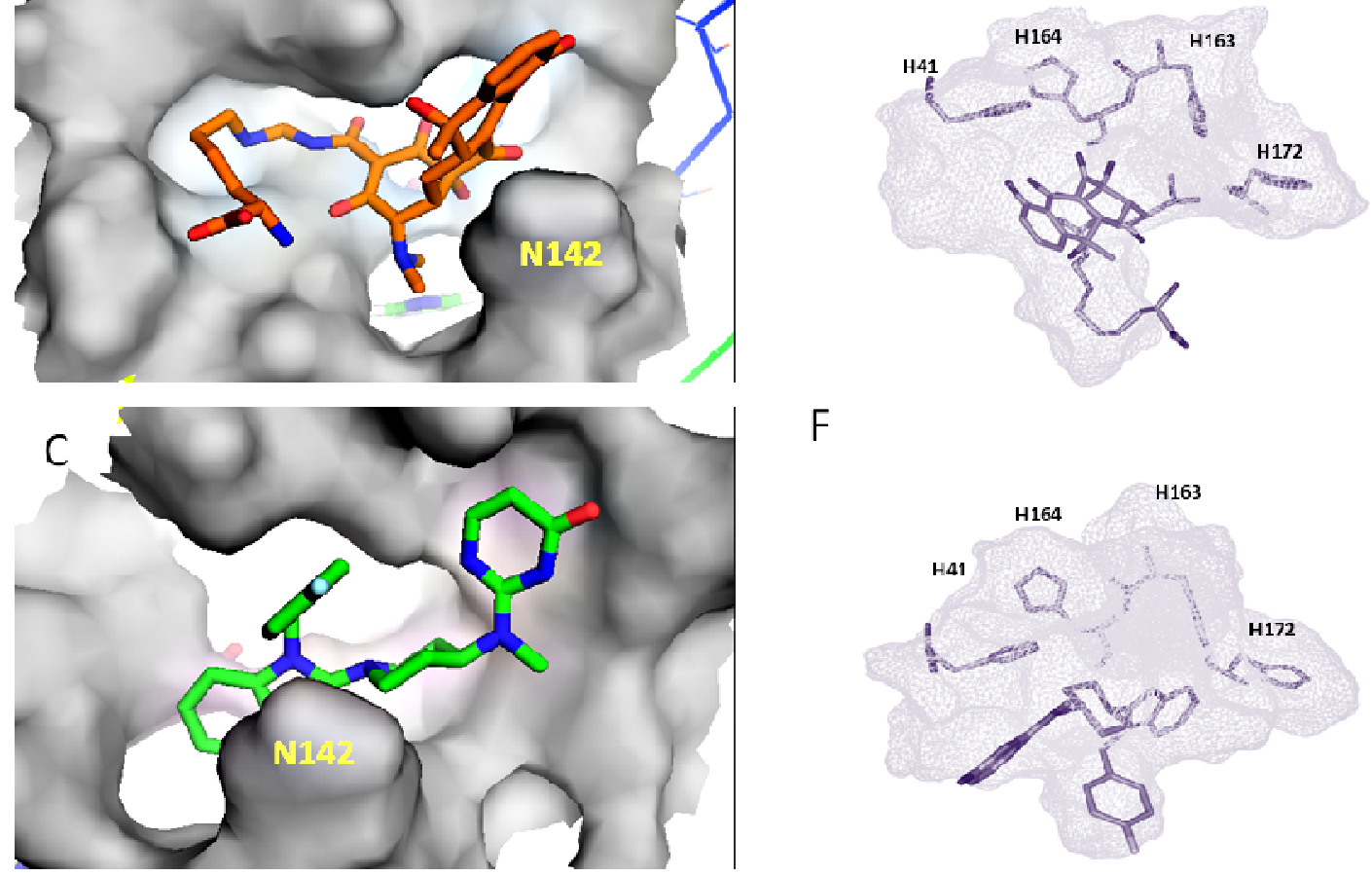

$\mathrm{F}$

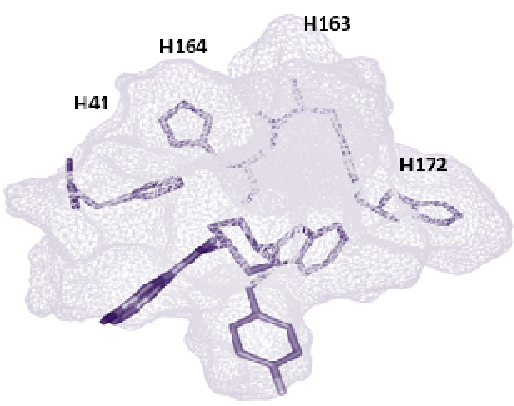

Figure 4: Pymol solid surface representations of binding mode of N3 compound (A), Lymecycline (B) and Mizolastine (C). Binding pocket prediction of N3 (D), Lymecycline (E) and Mizolastine $(\mathrm{F})$ within $6 \mathrm{lu} 7$ pocket. Amino acid residues are labeled: N (Gln) and $\mathrm{H}$ (His).

\subsection{Pharmacokinetics properties}

Drug likeness and pharmacokinetics proprieties analysis showed that Mizolastine and Chloroquine had four interesting features; a high lipophilicity, bioavailability score of 0.55 , and higher gastrointestinal (GI) absorption. Otherwise, Lymecycline is soluble compared to Chloroquine, Indinavir and N3. The absorption is low and presents a bioavailability score of 
$\approx 0.1$ with N3 compound. Interestingly, Lymecycline and Chloroquine are not substrates of Pglycoprotein compared to other drugs (Table IV). Indeed, P-glycoprotein is a multidrug transporter which is apically expressed in the gastrointestinal tract, liver, kidney and brain endothelium. Consequently, P-glycoprotein plays an important role in the oral bioavailability, CNS (Central Nervous System) distribution biliary and renal elimination of drugs which are substrates of this transporter. It has been reported that Indinavir and Saquinavir displayed a reduced antiviral activity. Both drugs partially recover the ability to inhibit the replication of HIV-1 in the presence of Verapamil (P-glycoprotein Inhibitor). Thus, P-gp expression may affect the activity of antiviral drugs (Maffeo et al., 2004; Turriziani et al., 2000).

Toxicity data analysis showed that Lymecycline $\left(\mathrm{LD}_{50}=3000 \mathrm{mg} / \mathrm{kg}\right)$ and Mizolastine $\left(\mathrm{LD}_{50}=450 \mathrm{mg} / \mathrm{kg}\right)$ are safe to used compared to Chloroquine $\left(\mathrm{LD}_{50}=311 \mathrm{mg} / \mathrm{kg}\right)$. In addition, several studies reported that Tetracyclines had clinical utility against intracellular parasites such as malaria, Chlamydia and a-proteobacteria (Nelson \& Ismail, 2007).

Table IV: Drug likeliness, pharmacokinetic and $\mathrm{LD}_{50}$ proprieties of the eight selected drugs P-gp: P-glycoprotein, GI: Gastrointestinal, BBB: Blood Brain Barrier, LD $\mathbf{5}_{\mathbf{5 0}}$ : Lethal dose, 50\%.

\begin{tabular}{|c|c|c|c|c|c|c|c|}
\hline Compounds & $\begin{array}{l}\text { Water } \\
\text { solubility }\end{array}$ & $\begin{array}{l}\text { Lipophilicity } \\
\text { Consensus } \\
\log \mathrm{P}_{\mathrm{o} / \mathrm{w}}\end{array}$ & $\begin{array}{l}\text { GI } \\
\text { absorption }\end{array}$ & $\begin{array}{l}\text { BBB } \\
\text { permeability }\end{array}$ & $\begin{array}{l}\text { P-gp } \\
\text { substrate }\end{array}$ & $\begin{array}{l}\text { Bioavailability } \\
\text { score }\end{array}$ & $\begin{array}{l}\mathrm{LD}_{50} \\
\mathrm{mg} / \mathrm{kg}\end{array}$ \\
\hline $\mathrm{N} 3$ & Poorly soluble & 2.69 & Low & No & Yes & 0.17 & 4000 \\
\hline Indinavir & Poorly soluble & 2.78 & High & No & Yes & 0.55 & 5000 \\
\hline Chloroquine & Poorly soluble & 4.15 & High & Yes & No & 0.55 & 311 \\
\hline Lymecycline & Soluble & -1.86 & Low & No & No & 0.11 & 3000 \\
\hline Mizolastine & Poorly soluble & 3.28 & High & Yes & Yes & 0.55 & 450 \\
\hline Quinine & $\begin{array}{l}\text { Moderately } \\
\text { soluble }\end{array}$ & 2.81 & High & Yes & No & 0.55 & 263 \\
\hline Cetirizine & $\begin{array}{l}\text { Moderately } \\
\text { soluble }\end{array}$ & 2.56 & High & Yes & Yes & 0.55 & 365 \\
\hline Nitazoxanide & Soluble & 1.16 & Low & No & No & 0.55 & 1350 \\
\hline Doxycycline & Soluble & -0.34 & Low & No & Yes & 0.11 & 2240 \\
\hline
\end{tabular}




\subsection{MD simulation analysis}

Molecular dynamic is a state-of-the-art simulation method for studying the physical motion and trajectory of the atoms in the presence of other molecules along with the various interactions within a system. It helps to follow and understand the structural features and conformational dynamics in the system. Thus, to validate the stability of the system and to probe ligand induced perturbations, MD simulation was performed with two best compounds as a function of time. The MD trajectories were examined based on various parameters including Root Mean Square Deviation (RMSD), Root Mean Square Fluctuation (RMSF), Radius of Gyration ( $\mathrm{Rg}$ ), Inter-molecular hydrogen bond interaction and occupancy. Moreover, binding free energy calculations were also performed.

RMSD monitors the deviations in average distance between the atoms of target protein during simulation with respect to initial docking structure/ reference frame. In short it is the deviation of the 3D structure over time. It provides insight into the system's stability, equilibrium and convergence whereas, the smaller fluctuations and constant backbone atoms $(\mathrm{C}, \mathrm{C} \alpha, \mathrm{N}$, and O) RMSD, is indicative of the stable system. As described in figure 5 (A) after an initial period of fluctuation both systems attained equilibrium during the last $20 \mathrm{~ns}$ of the simulation run. In general, the $\mathrm{M}^{\text {pro }}$ and Lymecycline system displayed higher fluctuation, whilst in comparison the lowest deviation was observed for $\mathrm{M}^{\text {pro }}$-Mizolastine complex indicating better binding. For Lymecycline complex during the initial frames continuous increase in RMSD value was observed in the range of $<2-4 \AA$ however, in the last $15 \mathrm{~ns}$ trajectories the system obtained stability with the deviation of $<3 \AA$. In comparison, for Mizolastine complex, after gradual increase in fluctuation during the initial $45 \mathrm{~ns}$ time period, the system attained equilibrium state in the remainder MD trajectories. The average RMSD for $\mathrm{M}^{\text {pro }}$-Lymecycline and $\mathrm{M}^{\text {pro }}$-Mizolastine complex was maintained at 2.99 0.48 and $2.46 \pm 0.33 \AA$, which implies that both systems folded to a more stable structure compared to initial structure. Additionally, there was not much deviation between average and observed RMSD of protein at the end of the $75 \mathrm{~ns}$ simulation and for both systems the RMSD during the whole run was $<4 \AA$ which is in acceptable range.

RMSF analysis is highly suitable to calculate the time dependent fluctuations in each residue, in turn is an essential parameter to determine the protein's flexibility. The RMSF of backbone atoms was calculated for $\mathrm{M}^{\text {pro }}$ with 306 residues with the two potential inhibitors. As illustrated in Figure 5 (B), both complexes had almost similar fluctuations trend. For most of the protein residues the observed RMSF value was lower than $2 \AA$. Whereas, the residues interacting with the ligands in the active site were found stable and displayed little fluctuations over time indicating the stable nature of compounds with target protein. In contrast the main fluctuations corresponded to the region that were distant from the ligand active site and others were found around the flexible loop region. Furthermore, the RMSF fluctuations in the Mizolastine complex was observed to be lower than the Lymecycline complex, suggesting that it had relatively lower structural mobility than the Lymecycline. The 
average RMSF values were $1.57 \pm 0.72$ and $1.32 \pm 0.56$ for Lymecycline and Mizolastine respectively.

The $\mathrm{Rg}$ is a parameter to assess the compactness and overall dimension of the protein which in turn signifies folding and unfolding of the protein. The lower the gyration values the more folded the protein is and vice versa. Therefore, $\mathrm{Rg}$ was calculated to determine whether the tested drugs maintained the folding of the system. The gyration graph for backbone carbon atoms of the protein relative to time is presented in the figure $5(\mathrm{C})$. The $\mathrm{Rg}$ values for both the systems range from 22-22.75 $\AA$ with an average score of 22.45 $0.14 \AA$ for Lymecycline and $22.24 \pm 0.11 \AA$ for Mizolastine. As evident from the plot negligible unfolding was observed for the lymecycline complex in contrast the Mizolastine complex attained more compacted form as the MD simulation progressed, indicating a well converged system. 


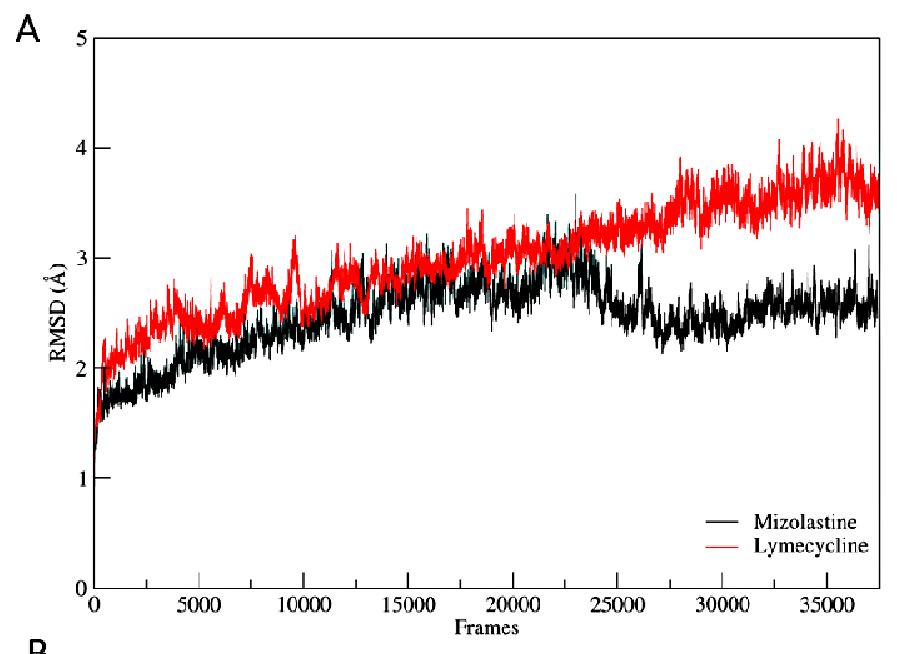

B
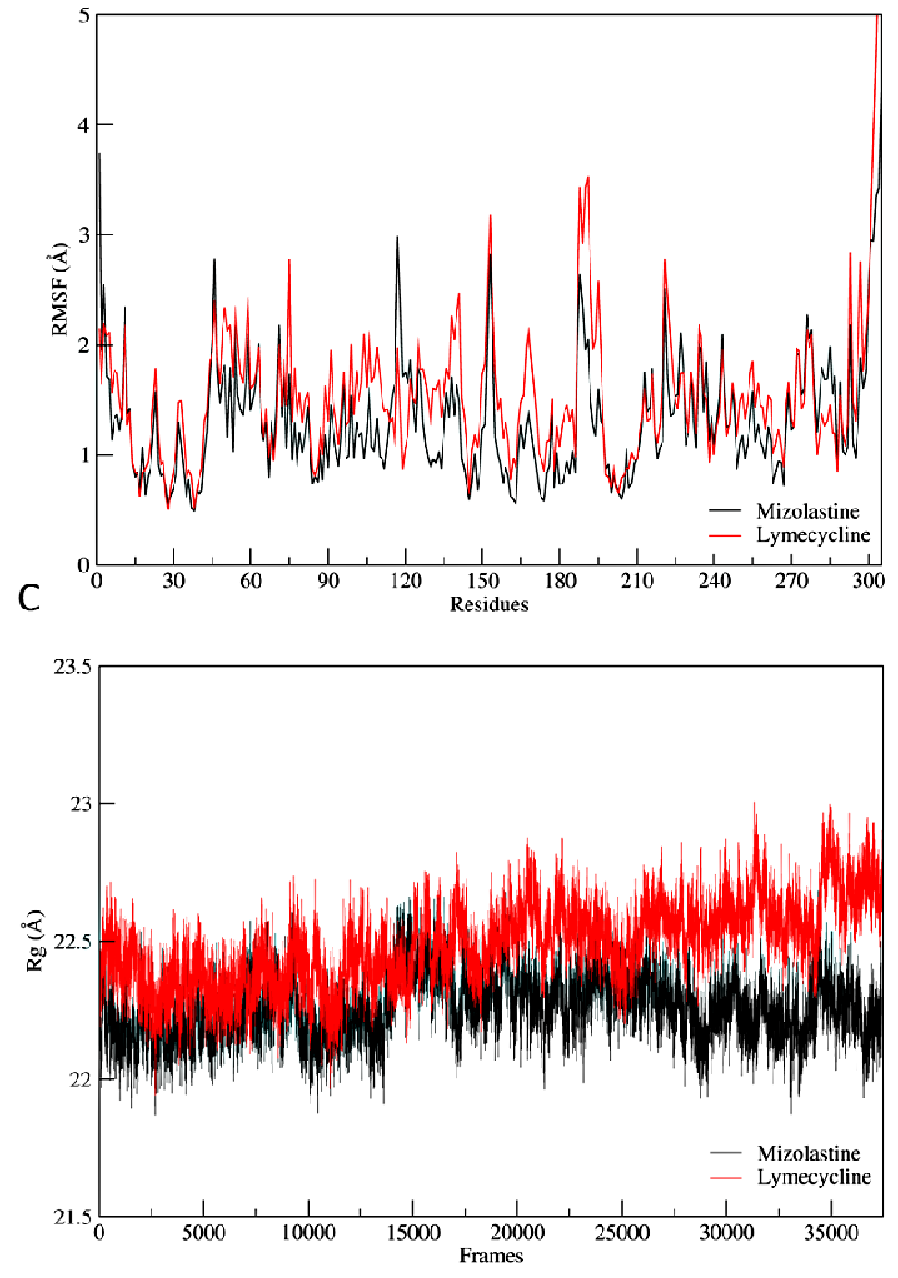

Figure 5: Time evolution plots of Molecular Dynamics Simulation trajectories of $\mathrm{M}^{\mathrm{pro}}$-Lymecycline complex and $\mathrm{M}^{\text {pro }}$-Mizolastine complex (A) Root Mean Square Deviation (RMSD), (B) Root Mean Square Fluctuation (RMSF) and (C) Radius of Gyration $(\mathrm{Rg})$. (500 frames $=1 \mathrm{~ns})$. 


\subsection{Inter-molecular interactions and hydrogen bond occupancy}

Generally, Protein-ligand interaction is stabilized by different types of weak interactions with hydrogen bonding contacts being the most important interaction. Hydrogen bond analysis was performed for both the complexes, with the occupancies reported in Table V. In general Hbond patterns were observed with various active site residues during simulation. In the MproLymecycline complex the active residues engaged in H-bond by Lymecycline were N142, H164, E166, L167, Q189 and Q192. The highest occupancy was observed for H164 (27.81\%), followed by E166 (9.09\%). The molecular interaction diagram (Figure. 6A) indicated that terminal amide $(\mathrm{NH})$ from Lymecycline contributed to the formation of two hydrogen bonds with E166 and G170. Moreover, Alkyl Hydroxyl substitution on benzene ring (Phenol ring) establishes H-bond contact with H164.

Mizolastine was found to make H-bond interaction with G143 (24.91\%), T190 (0.42\%) and C145 (0.81\%) from the active site. Furthermore, T25, T26, T45 and S46 were also involved. To investigate the stability of interactions and to explore binding mode, post MD simulation molecular interactions analysis was also carried out. As depicted in figure 6 (B) three hydrogen bonds were observed. The Imidazole ring from benzimidazole scaffold contributes to the hydrogen bond with $\mathrm{C} 145$ and G143. Another H-bond was formed between the pyrimidinone ring and T26 $(0.91 \%)$. It is important to note here that from the H-bond interactions analyzed in docking simulation only the interaction with G143 was maintained till the end of the simulation. For T24 the H-bond occupancy found was $18.53 \%$ however the distance found increased from 2.1 before MD simulation to $3.6 \AA$ A post MD simulation.

Table V: Hydrogen bonds between Lymecycline and Mizolastine with SARS-CoV-2 $\mathrm{M}^{\text {pro }}$ that found with at least $0.25 \%$ occupancy throughout $75 \mathrm{~ns}$ simulation run.

\begin{tabular}{|c|c|c|c|}
\hline Complexes & $\begin{array}{l}\text { Hydrogen bond Formation } \\
\text { Acceptor-DonorH/Donar }\end{array}$ & $\begin{array}{c}\text { Distance } \\
(\AA)\end{array}$ & $\begin{array}{c}\text { Occupancy } \\
(\%)\end{array}$ \\
\hline \multirow{23}{*}{$\mathrm{M}^{\mathrm{pro}}$-Lymecycline } & HID_164@O-Lymecycline@H77/Lymecycline@O40 & 2.73 & 27.81 \\
\hline & GLU_166@OE1-Lymecycline@H70/Lymecycline@O27 & 2.61 & 9.09 \\
\hline & GLU_166@OE2-Lymecycline@H70/Lymecycline@O27 & 2.62 & 5.01 \\
\hline & GLN_189@OE1-Lymecycline@H71/Lymecycline@O31 & 2.72 & 4.93 \\
\hline & HID_164@O-Lymecycline@H54/Lymecycline@ O12 & 2.64 & 4.54 \\
\hline & GLU_166@OE1-Lymecycline@H68/Lymecycline@N24 & 2.84 & 4.46 \\
\hline & Lymecycline@O15-GLU_166@H/GLU_166@N & 2.88 & 4.46 \\
\hline & Lymecycline@O29-GLN_189@HE22/GLN_189@NE2 & 2.86 & 4.25 \\
\hline & Lymecycline@O29-GLN_189@HE21/GLN_189@NE2 & 2.85 & 4.18 \\
\hline & GLU_166@O-Lymecycline@H58/Lymecycline@N18 & 2.88 & 3.82 \\
\hline & GLU_166@O-Lymecycline@H68/Lymecycline@ N24 & 2.88 & 2.97 \\
\hline & Lymecycline@O31-GLN_189@HE22/GLN_189@NE2 & 2.89 & 2.48 \\
\hline & GLU_166@OE2-Lymecycline@H68/Lymecycline@N24 & 2.84 & 2.17 \\
\hline & Lymecycline@O12-GLU_166@H/GLU_166@N & 2.92 & 1.86 \\
\hline & GLU_166@OE1-Lymecycline@H69/Lymecycline@N24 & 2.84 & 1.69 \\
\hline & GLU_166@O-Lymecycline@H54/Lymecycline@O12 & 2.72 & 1.25 \\
\hline & GLU_166@OE2-Lymecycline@H69/Lymecycline@N24 & 2.85 & 1.19 \\
\hline & GLU_47@OE2-Lymecycline@H73/Lymecycline@O37 & 2.66 & 0.97 \\
\hline & Lymecycline@O26-HIE_163@HE2/HIE_163@NE2 & 2.87 & 0.92 \\
\hline & Lymecycline@O26-GLN_189@HE22/GLN_189@NE2 & 2.86 & 0.90 \\
\hline & MET_49@O-Lymecycline@H71/Lymecycline@O31 & 2.71 & 0.86 \\
\hline & Lymecycline@O26-ASN_142@H/ASN_142@N & 2.88 & 0.86 \\
\hline & Lymecycline@O33-GLN_189@HE22/GLN_189NE2 & 2.86 & 0.78 \\
\hline
\end{tabular}




\begin{tabular}{|c|c|c|c|}
\hline & LEU_167@O-Lymecycline@H69/Lymecycline@ N24 & 2.90 & 0.74 \\
\hline & GLN_189@OE1-Lymecycline@H58/Lymecycline@N18 & 2.89 & 0.73 \\
\hline & ASN_142@OD1-Lymecycline@H58/Lymecycline@N18 & 2.89 & 0.68 \\
\hline & Lymecycline@O26-ASN_142@HD21/ASN_142@ND2 & 2.87 & 0.67 \\
\hline & ASN_142@OD1-Lymecycline@H68/Lymecycline@N24 & 2.88 & 0.63 \\
\hline & Lymecycline@O27-HIE_172@HE2/HIE_172@NE2 & 2.90 & 0.60 \\
\hline & GLU_47@OE1-Lymecycline@H73/Lymeycline@O37 & 2.69 & 0.55 \\
\hline & Lymecycline@O26-GLN_192@H/GLN_192@N & 2.88 & 0.51 \\
\hline & Lymecycline@O29-SER_46@HG/SER_46@OG & 2.77 & 0.50 \\
\hline & ASN_142@OD1-Lymecycline@H69/Lymecycline@N24 & 2.87 & 0.47 \\
\hline & Lymecycline@O33-ASN_142@HD2/ASN_142@ND2 & 2.86 & 0.42 \\
\hline & LEU_167@O-Lymecycline@H68/Lymecycline@N24 & 2.88 & 0.42 \\
\hline & GLN_189@OE1-Lymecycline@H54/Lymecycline@O12 & 2.63 & 0.38 \\
\hline & Lymecycline@O27-GLN_192@H/GLN_192@N & 2.92 & 0.37 \\
\hline & GLU_166@O-Lymecycline@H69/Lymecycline@N24 & 2.88 & 0.36 \\
\hline & Lymecycline@O36-GLN_189@HE21/GLN_189@NE2 & 2.91 & 0.33 \\
\hline & SER_46@OG-Lymecycline@H73/Lymecycline@O37 & 2.83 & 0.28 \\
\hline & Lymecycline@O26-ASN_142@HD22/ASN_142@ND2 & 2.88 & 0.26 \\
\hline & Lymecycline@O27-HIE_163@HE2/HIE_163@NE2 & 2.90 & 0.25 \\
\hline & Lymecycline@O26-SER_46@HG/SER_46@OG & 2.76 & 0.25 \\
\hline \multirow{15}{*}{$\mathbf{M}^{\text {pro }}$-Mizolastine } & Mizolastine@N15-GLY_143@H/GLY_143@N & 2.92 & 24.91 \\
\hline & Mizolastine@O8-THR_24@HG1/THR_24@OG1 & 2.73 & 18.53 \\
\hline & Mizolastine@O8-SER_46@H/SER_46@N & 2.86 & 14.79 \\
\hline & THR_24@O-Mizolastine@H38/Mizolastine@N9 & 2.88 & 5.67 \\
\hline & SER_46@OG-Mizolastine@H38/Mizolastine@N9 & 2.90 & 3.47 \\
\hline & Mizolastine@O8-THR_45@HG1/THR_45@OG1 & 2.74 & 1.43 \\
\hline & THR_25@OG1-Mizolastine@H38/Mizolastine@N9 & 2.88 & 0.99 \\
\hline & Mizolastine@N4-THR_26@H/THR_26@N & 2.94 & 0.91 \\
\hline & Mizolastine@N15-CYS_145@H/CYS_145@N & 2.95 & 0.81 \\
\hline & Mizolastine@O8-SER_46@HG/SER_46@OG & 2.77 & 0.79 \\
\hline & Mizolastine@N4-THR_25@HG1/THR_25@OG1 & 2.88 & 0.48 \\
\hline & Mizolastine@F28-THR_190@HG1/THR_190@OG1 & 2.84 & 0.42 \\
\hline & THR_44@OG1-Mizolastine@H38/Mizolastine@N9 & 2.92 & 0.27 \\
\hline & Mizolastine@O8-THR_25@HG1/THR_25@OG1 & 2.75 & 0.26 \\
\hline & Mizolastine@O8-THR_26@H/THR_26@N & 2.86 & 0.25 \\
\hline
\end{tabular}


A
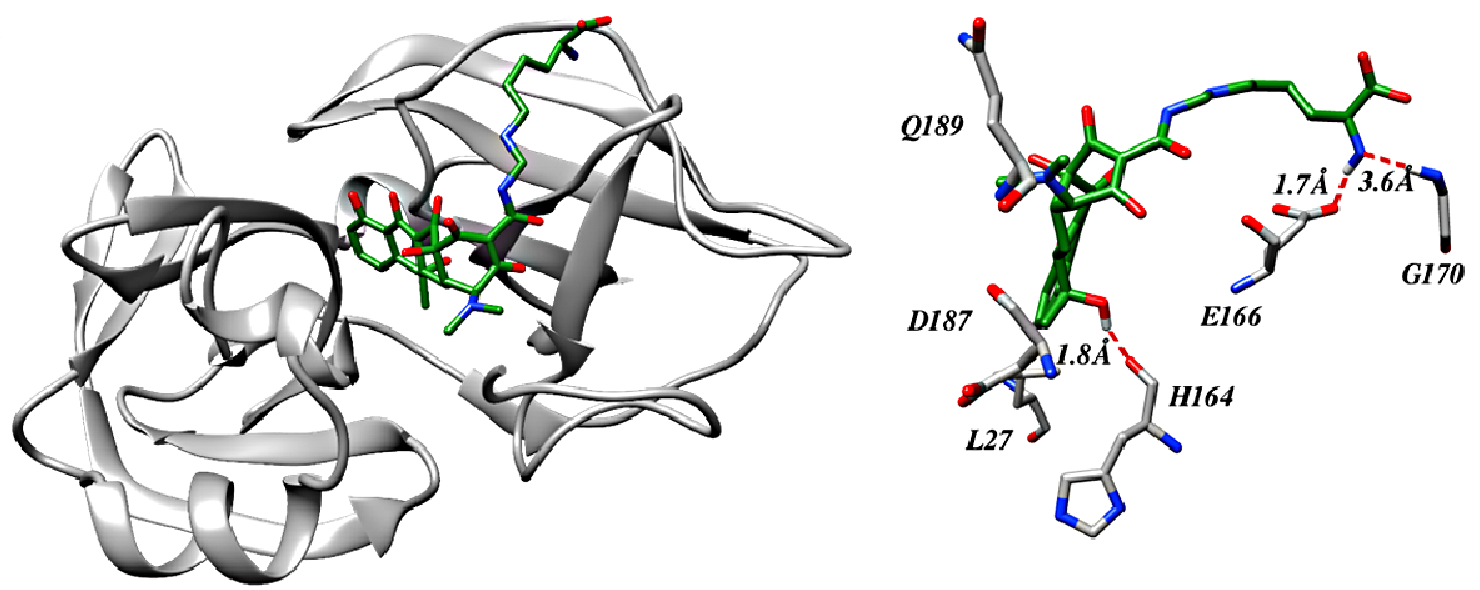

B
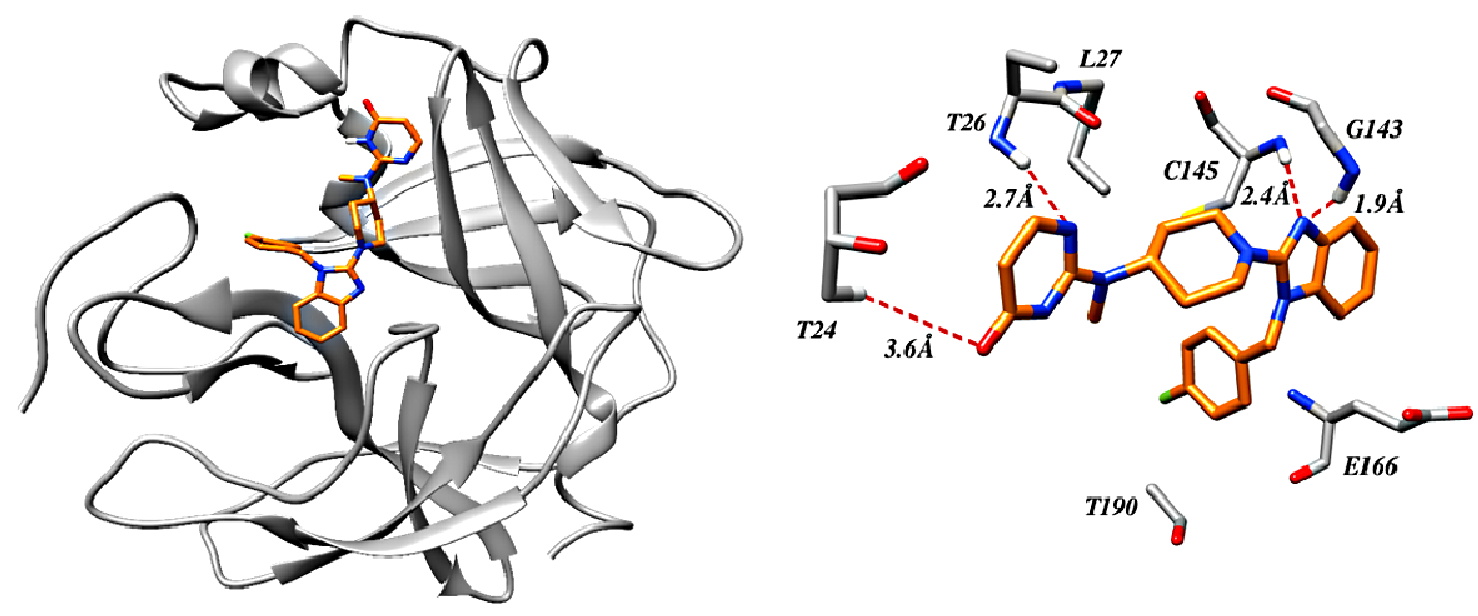

Figure 6: Post MD intermolecular interaction analysis. (A) Binding orientation of Lymecycline and mode of interaction with SARS-CoV-2 $\mathrm{M}^{\text {pro }}$. (B) Binding orientation and mode interaction of Mizolastine with SARS-CoV-2 $\mathrm{M}^{\mathrm{pro}}$. 


\subsection{Free energy Calculations for Protein-ligand Binding}

Free energy calculations are a collection of methods used to envisage ligand binding affinities by considering several atomic level interactions that could be responsible for the affinity of ligand toward targeted protein. Thus, to understand the biophysical basis of interaction between Lymecycline and Mizolastine with main protease in further detail MM/PBSA calculations were carried out. For each complex non-polar solvation energy $\left(G_{\text {nonpolar }}\right)$, polar solvation $\left(\mathrm{G}_{\mathrm{PB}}\right)$, electrostatic $\left(\mathrm{E}_{\text {elec }}\right)$, van der waals $\left(\mathrm{E}_{\mathrm{vdw}}\right)$ and binding free energy $\left(\Delta \mathrm{G}_{\text {binding }}\right)$ were calculated. A summary of individual components involved in the binding free energy of tested inhibitors with main protease is shown graphically in Figure 7 with the data listed in Table VI.

It is evident from the data that the binding of inhibitors to target protein is favored by nonpolar solvation energy, intermolecular electrostatic and van der Waals interactions. In contrast, complexation is disfavored by polar solvation energy. The calculated $\Delta \mathrm{G}$ binding energy for Lymecycline and Mizolastine with target protein was found to be $-23.41 \pm 7.48$ and $-27.84 \pm 3.89 \mathrm{kcal} / \mathrm{mol}$, respectively.

Table VI: The binding energies (KJ/mol) for Lymecycline and Mizolastine combined with SARS-CoV-2 main-protease (PDB ID 6lu7) using MM/PBSA from the snapshots extracted from 65-75 ns of MD simulation trajectory.

\begin{tabular}{|c|c|c|}
\hline \multirow{2}{*}{$\begin{array}{c}\text { Energy } \\
\text { Components }\end{array}$} & \multicolumn{2}{|c|}{ Complexes } \\
\cline { 2 - 3 } & 6lu7-Lymecycline & 6lu7-Mizolastine \\
\hline $\mathrm{E}_{\mathrm{vdw}}$ & $-44.61 \pm 5.13$ & $-43.55 \pm 3.11$ \\
\hline $\mathrm{E}_{\mathrm{elec}}$ & $-30.82 \pm 14.76$ & $-30.08 \pm 5.14$ \\
\hline $\mathrm{G}_{\mathrm{PB}}$ & $56.61 \pm 13.78$ & $50.11 \pm 5.00$ \\
\hline $\mathrm{G}_{\text {nonpolar }}$ & $-4.60 \pm 0.43$ & $-4.33 \pm 0.20$ \\
\hline$\Delta$ Ggas & $-75.42 \pm 16.96$ & $-73.62 \pm 6.05$ \\
\hline$\Delta$ Gsolv & $52.01 \pm 13.46$ & $45.78 \pm 4.91$ \\
\hline$\Delta$ Total & $-23.41 \pm 7.48$ & $-27.84 \pm 3.89$ \\
\hline
\end{tabular}




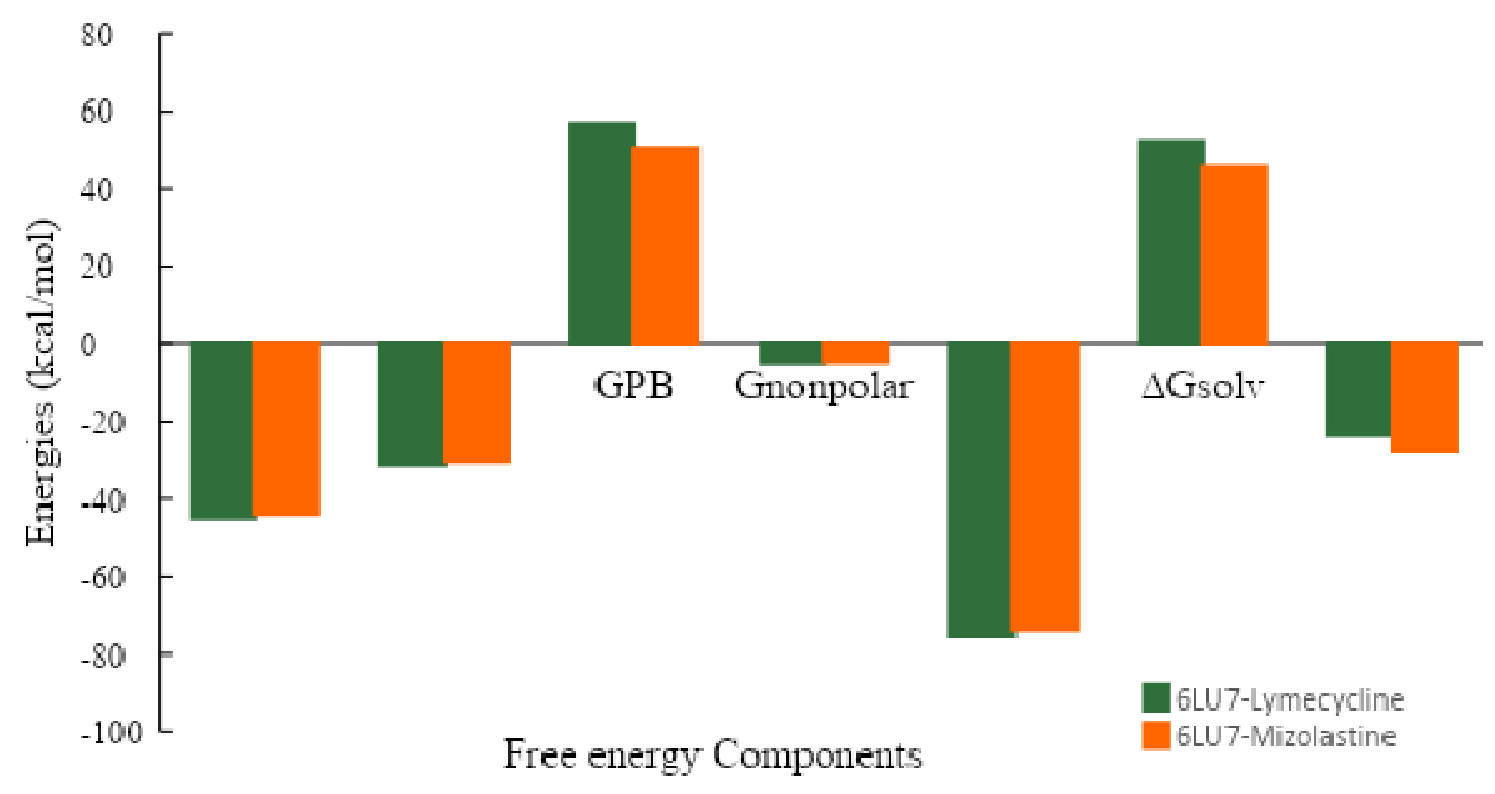

Figure 7: The energy contributions $(\mathrm{KJ} / \mathrm{mol})$ of Lymecycline and Mizolastine combined with SARS-CoV-2 main-protease (PDB ID 6lu7) in MM/PBSA assay.

\section{CONCLUSION}

This blind molecular docking study proposes potential available approved drugs: Lymecycline and Mizolastine as prospective inhibitors of SARS-CoV-2 $\mathrm{M}^{\text {pro }}$. The estimated free energy of binding of these two drugs is in the range of -8.87 and $-8.71 \mathrm{kcal} / \mathrm{mol}$, proffering the spontaneous and energetically favored production of protein ligand complex. Molecular dynamic study concludes that Mizolastine can serve as a potential $\mathbf{M}^{\text {pro }}$ inhibitor based on its stable nature during a long term molecular dynamic simulation. Though the maximum number of hydrogen bonds were formed by Lymecycline during the simulation yet the data from RMSD, RMSF, Rg and MM/PBSA indicate Mizolastine as more potent candidate for further in vitro testing and Anti SARS-CoV-2 therapeutics development. 


\begin{tabular}{|c|c|}
\hline \multicolumn{2}{|l|}{ Abbreviations } \\
\hline WHO & World Health Organization \\
\hline PHEIC & Public Health Emergency of International Concern \\
\hline SARS-CoV & Severe Acute Respiratory Syndrome Virus \\
\hline MERS-CoV & Middle East Respiratory Syndrome Virus \\
\hline SARS-CoV-2 & Severe Acute Respiratory Syndrome Cornonavirus-2 \\
\hline COVID-19 & Coronavirus Disease 2019 \\
\hline $\mathrm{M}^{\mathrm{pro}} / \mathbf{3 C L}$ & Protease/3-Chymotrypsin-Like protease \\
\hline RdRp & RNA-dependant RNA polymerase \\
\hline PLpro & Papaine-Like protease \\
\hline MM & Molecular Mass \\
\hline PDB & Protein Data Bank \\
\hline RMSD & Root Mean Square Deviation \\
\hline RMSF & Root Mean Square Fluctuation \\
\hline MD & Molecular Dynamics \\
\hline ADMET & Absorption, Distribution, Metabolism, Excretion and Toxicity \\
\hline DL50 & Lethal dose, $50 \%$. \\
\hline P-gp & P-glycoprotein \\
\hline GI & Gastrointestinal \\
\hline BBB & Blood Brain Barrier \\
\hline
\end{tabular}




\section{REFERENCES}

Aanouz, I., Belhassan, A., El Khatabi, K., Lakhlifi, T., El Idrissi, M., \& Bouachrine, M. (2020). Moroccan Medicinal plants as inhibitors of COVID-19: Computational investigations. Journal of Biomolecular Structure and Dynamics, (just-accepted), 1-12.

Anand, K., Ziebuhr, J., Wadhwani, P., Mesters, J. R., \& Hilgenfeld, R. (2003). Coronavirus main proteinase (3CLpro) structure: basis for design of anti-SARS drugs. Science, 300 (5626), $1763-1767$.

Anthony, S. J., Johnson, C. K., Greig, D. J., Kramer, S., Che, X., Wells, H., Hicks, A.L., Joly, D.O., Wolfe, N.D., Daszak, P., Karesh, W., Lipkin, W.I., Morse, S.S., Mazet, J.A.K., \& Goldstein T. (2017). Global patterns in coronavirus diversity. Virus evolution, 3(1).

Bernstein, F.C., Koetzle, T.F., Williams, G.J., Meyer, Jr. E.F., Brice, M.D., Rodgers, J.R., Kennard, O., Shimanouchi, T., \& Tasumi, M. (1977). The Protein Data Bank: A computer $\square$ based archival file for macromolecular structures. European journal of biochemistry, 80(2), 319-324.

Boopathi, S., Poma, A. B., \& Kolandaivel, P. (2020). Novel 2019 Coronavirus Structure, Mechanism of Action, Antiviral drug promises and rule out against its treatment. Journal of Biomolecular Structure and Dynamics, (just-accepted), 1-14.

Case, D. A., Cheatham III, T. E., Darden, T., Gohlke, H., Luo, R., Merz Jr, K. M., Onufriev, A., Simmerling, C., Wang, B., \& Woods, R. J. (2005). The Amber biomolecular simulation programs. Journal of computational chemistry, 26(16), 1668-1688.

Chang, Y.C., Tung, Y.A., Lee, K.H., Chen, T.F., Hsiao, Y.C., Chang, H.C., Hsieh, T.T., Su, C.H., Wang, S.S., Yu, J.Y., Shih, S.H., Lin, Y.H., Lin, Y.H., Tu, Y.C.E., Hsu, C.H., Juan, H.F., Tung, C.W., \& Chen, C.Y. (2020). Potential therapeutic agents for COVID-19 based on the analysis of protease and RNA polymerase docking.

Daina, A., Michielin, O., \& Zoete, V. (2017). SwissADME: a free web tool to evaluate pharmacokinetics, drug-likeness and medicinal chemistry friendliness of small molecules. Scientific reports, 7, 42717.

Darden, T., York, D., \& Pedersen, L. (1993). Particle mesh Ewald: An N. log (N) method for Ewald sums in large systems. The Journal of chemical physics, 98(12), 10089-10092.

DeLano W. (2002). Pymol: An open-source molecular graphics tool. CCP4 Newsletter on protein crystallography, 40, 82-92.

Drwal, M. N., Banerjee, P., Dunkel, M., Wettig, M. R., \& Preissner, R. (2014). ProTox: a web server for the in silico prediction of rodent oral toxicity. Nucleic acids research, 42(W1), W53-W58. 
Elmezayen, A. D., Al-Obaidi, A., Şahin, A. T., \& Yelekçi, K. (2020). Drug repurposing for coronavirus (COVID-19): in silico screening of known drugs against coronavirus 3CL hydrolase and protease enzymes. Journal of Biomolecular Structure and Dynamics, (justaccepted), 1-12.

Elmezayen, A. D., Al-Obaidi, A., Şahin, A. T., \& Yelekçi, K. (2020). Drug repurposing for coronavirus (COVID-19): in silico screening of known drugs against coronavirus 3CL hydrolase and protease enzymes. Journal of Biomolecular Structure and Dynamics, (justaccepted), 1-12.

Fährrolfes, R., Bietz, S., Flachsenberg, F., Meyder, A., Nittinger, E., Otto, T., Volkamer, A., \& Rarey, M. (2017). Proteins Plus: a web portal for structure analysis of macromolecules. Nucleic acids research, 45(W1), W337-W343.

Gorbalenya, A.E., Baker, S.C., \& Baric, R.S. (2020). The species Severe acute respiratory syndrome-related coronavirus: classifying 2019-nCoV and naming it SARS-CoV-2. Nature Microbiology, 5(4), 536.

Grosdidier, A., Zoete, V., \& Michielin, O. (2011). SwissDock, a protein-small molecule docking web service based on EADock DSS. Nucleic acids research, 39, 270-277.

Humphrey, W., Dalke, A., \& Schulten, K. (1996). VMD: visual molecular dynamics. Journal of molecular graphics, 14(1), 33-38.

Islam, R., Parves, R., Paul, A. S., Uddin, N., Rahman, M. S., Mamun, A. A., Hossain , N., Ali Ackas \& Halim, M. A. (2020). A molecular modeling approach to identify effective antiviral phytochemicals against the main protease of SARS-CoV-2. Journal of Biomolecular Structure and Dynamics, (just-accepted), 1-20.

Jin, Z., Du, X., Xu, Y., Deng, Y., Liu, M., Zhao,Y., Zhang, B., Li, X., Zhang, L., Peng, C., Duan, Y., Yu, J., Wang, L., Yang, K., Liu, F., Jiang, R., Yang, X., You, T., Liu, X., Yang, X., Bai, F., Liu, H., Liu, X., Luke, W.G., Xu, W., Xia, G., Qin, C., Shi, Z., Jiang, H., Rao, Z.,\& Yang H. Structure of $\mathrm{M}^{\text {pro }}$ from COVID-19 virus and discovery of its inhibitors. bioRxiv, 2020.

Khan, M. T., Ali, A., Wang, Q., Irfan, M., Khan, A., Zeb, M. T., Zhang, YJ, Chinnasamy, S \& Wei, D. Q. (2020). Marine natural compounds as potents inhibitors against the main protease of SARS-CoV-2. A molecular dynamic study. Journal of Biomolecular Structure and Dynamics, (just-accepted), 1-14.

Khan, S. A., Zia, K., Ashraf, S., Uddin, R., \& Ul-Haq, Z. (2020). Identification of chymotrypsin-like protease inhibitors of SARS-CoV-2 via integrated computational approach. Journal of Biomolecular Structure and Dynamics, 1-10.

Kucharski, A. J., Russell, T. W., Diamond, C., Liu, Y., Edmunds, J., Funk, S., Eggo, R., \& Davies, N. (2020). Early dynamics of transmission and control of COVID-19: a mathematical modelling study. The lancet infectious diseases. 
Kupferschmidt, K \& Cohen J. (2020). Will novel virus go pandemic or be contained? Science, 367 (6478), $610-611$.

Liu, C., Zhou, Q., Li, Y., Garner, L. V., Watkins, S. P., Carter, L. J., Smoot, J., Gregg, A.C., Daniel, A.D., Jervey, S., \& Albaiu, D. (2020). Research and development on therapeutic agents and vaccines for COVID-19 and related human coronavirus diseases.

Maffeo, A., Bellomi, F., Solimeo, I., Bambacioni, F., Scagnolari, C., De, F. P., Dupuis, M.L., Cianfriglia, M., Antonelli, G., \& Turriziani, O. (2004). P-glycoprotein expression affects the intracellular concentration and antiviral activity of the protease inhibitor saquinavir in a $\mathrm{T}$ cell line. The new microbiologica, 27(2 Suppl 1), 119-126.

Maier, J. A., Martinez, C., Kasavajhala, K., Wickstrom, L., Hauser, K. E., \& Simmerling, C. (2015). ff14SB: improving the accuracy of protein side chain and backbone parameters from ff99SB. Journal of chemical theory and computation, 11(8), 3696-3713.

Miller III, B. R., McGee Jr, T. D., Swails, J. M., Homeyer, N., Gohlke, H., \& Roitberg, A. E. (2012). MMPBSA. py: an efficient program for end-state free energy calculations. Journal of chemical theory and computation, 8(9), 3314-3321.

Muralidharan, N., Sakthivel, R., Velmurugan, D., \& Gromiha, M. M. (2020). Computational studies of drug repurposing and synergism of lopinavir, oseltamivir and ritonavir binding with SARS-CoV-2 Protease against COVID-19. Journal of Biomolecular Structure and Dynamics, $1-6$.

Needle, D., Lountos, G. T., \& Waugh, D. S. (2015). Structures of the Middle East respiratory syndrome coronavirus 3C-like protease reveal insights into substrate specificity. Acta Crystallographica Section D: Biological Crystallography, 71(5), 1102-1111.

Nelson, M.L. \& Ismail M.Y. The Antibiotic and Nonantibiotic Tetracyclines. (2007). Paratek Pharmaceuticals, Inc., Boston, MA, USA. Elsevier Ltd.

Odhar, H.A., Ahjel, S.W., Albeer, A.A.M.A., Fadhil, A., Hashim, A.M.R., \& Humadi, S.S. (2020). Molecular docking and dynamics simulation of FDA approved drugs with the main protease from 2019 novel coronavirus. Bioinformation, 16 (3), 236-244.

Pettersen, E.F., Goddard, T.D., Huang, C.C., Couch, G.S., Greenblatt, D.M., Meng, E.C., \& Ferrin, T.E. (2004). UCSF Chimera a visualization system for exploratory research and analysis. Journal of computational chemistry, 25(13), 1605-1612.

Rodríguez-Morales, A. J., MacGregor, K., Kanagarajah, S., Patel, D., \& Schlagenhauf, P. (2020). Going global-Travel and the 2019 novel coronavirus. Travel medicine and infectious disease, 33, 101578.

Ryckaert, J. P., Ciccotti, G., \& Berendsen, H. J. (1977). Numerical integration of the cartesian equations of motion of a system with constraints: molecular dynamics of n-alkanes. Journal of computational physics, 23(3), 327-341. 
Srivastava, A.K., Kumar, A., Tiwari, G., Kumar, R., \& Misra, N. (2003). In Silico Investigations on the Potential Inhibitors for COVID-19 Protease. arXiv preprint arXiv, $10642,2020$.

Stierand, K., Maaß, P. C., \& Rarey, M. (2006). Molecular complexes at a glance: automated generation of two-dimensional complex diagrams. Bioinformatics, 22(14), 1710-1716.

Fricker, P. C., Gastreich, M., \& Rarey, M. (2004). Automated drawing of structural molecular formulas under constraints. Journal of chemical information and computer sciences, 44(3), 1065-1078.

Turriziani, O., Di Marco, P., Antonelli, G., \& Dianzani F. (2000). May the drug transporter P glycoprotein affect the antiviral activity of human immunodeficiency virus type 1 proteinase inhibitors?. Antimicrobial agents and chemotherapy, 44(2), 473-474.

Umesh, Kundu, D., Selvaraj, C., Singh, S. K., \& Dubey, V. K. (2020). Identification of new anti-nCoV drug chemical compounds from Indian spices exploiting SARS-CoV-2 main protease as target. Journal of Biomolecular Structure and Dynamics, (just-accepted), 1-9.

Volkamer, A., Kuhn, D., Grombacher, T., Rippmann, F., \& Rarey, M. (2012). Combining global and local measures for structure-based druggability predictions. Journal of chemical information and modeling, 52, 360-372.

Wang, J., Wolf, R. M., Caldwell, J. W., Kollman, P. A., \& Case, D. A. (2004). Development and testing of a general amber force field. Journal of computational chemistry, 25(9), 1157 1174.

Wishart, D.S., Knox, C., Guo, A.C., Shrivastava, S., Hassanali, M., Stothard, P., Chang, Z., \& Woolsey, J. 2006. DrugBank: a comprehensive resource for in silico drug discovery and exploration. Nucleic Acids Res, 34, 668-672.

Wu, F., Zhao, S., Yu, B., Chen, Y. M., Wang, W., Song, Z. G., Hu Y, Tao, Z.W., Tian, J.H., Pei, Y.Y., Yuan, M. L., Zhang, Y.L., Dai, F.H., Liu, Y., Wang, Q.M., Zheng, J.J., Xu, L., Holmes, E.C., \& Zhang, Y.Z. (2020). A new coronavirus associated with human respiratory disease in China. Nature, 579(7798), 265-269.

Yang, H., Yang, M., Ding, Y., Liu, Y., Lou, Z., Zhou, Z., Sun, L., Mo, L., Ye, S., Pang, H., Gao G.F., Anand, K., Bartlam, M., Hilgenfeld, R., \& Rao, Z. (2003). The crystal structures of severe acute respiratory syndrome virus main protease and its complex with an inhibitor. Proceedings of the National Academy of Sciences, 100(23), 13190-13195.

Zhou, P., Yang, X. L., Wang, X. G., Hu, B., Zhang, L., Zhang, W., Si, H.R., Zhu,Y., Li, B., Huang, C.L., Chen, H. D., Chen, J., Luo, Y., Guo, H., Jiang, R.D., Liu, M.K., Chen, Y., Shen, X.R., Wang, X., Zheng, X.S., Zhao, K., Chen, Q.J., Deng, F., Liu, L.L., Yan, B., Zhan, F.X., Wang, Y.Y., Xiao, G., \& Shi, Z.L. (2020). Discovery of a novel coronavirus associated with the recent pneumonia outbreak in humans and its potential bat origin. BioRxiv. 


\section{Disclosure statement}

The authors declare that the research was conducted in the absence of any commercial or financial relationships that could be construed as a potential conflict of interest. 